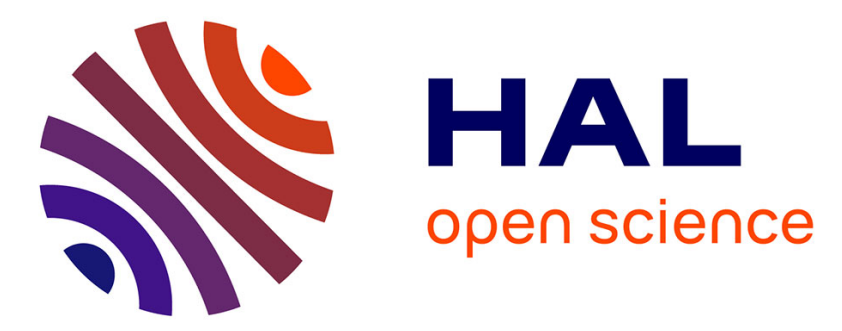

\title{
Design of a Two-Channel NMR Coil using an Impedance Transformation Approach
}

\author{
A.-L. Perrier, D. Grenier, A. Pouzin, F. Esclassan, N. Ravel, P. Litaudon, O. \\ Beuf
}

\section{- To cite this version:}

A.-L. Perrier, D. Grenier, A. Pouzin, F. Esclassan, N. Ravel, et al.. Design of a Two-Channel NMR Coil using an Impedance Transformation Approach. IEEE Sensors Journal, 2012, 12 (6), pp.1801-1808. 10.1109/JSEN.2011.2178237 . hal-00796845

\section{HAL Id: hal-00796845 \\ https://hal.science/hal-00796845}

Submitted on 20 Jun 2018

HAL is a multi-disciplinary open access archive for the deposit and dissemination of scientific research documents, whether they are published or not. The documents may come from teaching and research institutions in France or abroad, or from public or private research centers.
L'archive ouverte pluridisciplinaire HAL, est destinée au dépôt et à la diffusion de documents scientifiques de niveau recherche, publiés ou non, émanant des établissements d'enseignement et de recherche français ou étrangers, des laboratoires publics ou privés. 


\title{
Design of a Two-Channel NMR Coil using an Impedance Transformation Approach
}

\author{
A. L. Perrier, D. Grenier, A. Pouzin, F. Esclassan, N. Ravel, P. Litaudon and O. Beuf
}

\begin{abstract}
In the field of small-animal Magnetic Resonance Imaging (MRI), multi-channel coils are increasingly being used. Two-channel coils based on common conductor between the two elements are not considerably used and theoretical equations are not explicitly given. In this work, the design of a two-channel NMR coil based on common conductor for imaging applications have been carried out using an impedance transformation approach. The equations and simulations results at an operating frequency of $300 \mathrm{MHz}$ are confirmed by the characterization of the two-channel receiver coil prototype.
\end{abstract}

Index Terms - small animal MRI, tunable device, twochannels NMR coil.

\section{INTRODUCTION}

$\mathrm{N}$ uclear magnetic resonance (NMR) is a major noninvasive spectroscopic or imaging modality used on small animal for pre-clinical applications. In vivo anatomic, functional and metabolic information can be obtained to better understand biological phenomena, improve the diagnosis of a disease and follow therapeutic response before clinical implantation. Various NMR applications such as morphological high resolution imaging [1]-[3], spectroscopy [4]-[6] or functional imaging require 2011

Manuscript received June 15, 2011 and resubmitted September 20,

The authors thank the Institut Féfératif des Neurosciences de Lyon (IFNL) for financial support. This work was supported by an ANR grant (\#ANR-07-NEURO-030)

A. L. Perrier is with the Universite de Lyon, Creatis, CNRS UMR 5220, Inserm U630, INSA-Lyon, Université Lyon1, Villeurbanne, France (corresponding author to provide phone: 33 (0)4 724315 97; e-mail: anne-laure.perrier@univ-lyon1.fr).

D. Grenier is with the Universite de Lyon, Creatis, CNRS UMR 5220, Inserm U630, INSA-Lyon, Université Lyon1, Villeurbanne, France (e-mail: denis.grenier@univ-lyon1.fr).

A. Pouzin was with the Université de Lyon, Creatis, CNRS UMR 5220, Inserm U630, INSA-Lyon, Université Lyon1, Villeurbanne, France (e-mail: audrey.pouzin@gmail.com).

F. Esclassan is with Neurosciences Sensorielles, Comportement et Cognition; CNRS UMR 5020, Université Lyon 1, Institut Fédératif des Neurosciences de Lyon, Lyon, France (e-mail: fesclass@olfac.univlyon1.fr).

N. Ravel is with Neurosciences Sensorielles, Comportement et Cognition; CNRS UMR 5020, Université Lyon 1, Institut Fédératif des Neurosciences de Lyon, Lyon, France (e-mail: nadine.ravel@olfac.univlyon1.fr).

P. Litaudon is with Neurosciences Sensorielles, Comportement et Cognition; CNRS UMR 5020, Université Lyon 1, Institut Fédératif des Neurosciences de Lyon, Lyon, France (e-mail: litaudon@olfac.univlyon1.fr).

O. Beuf is with the Universite de Lyon, Creatis, CNRS UMR 5220, Inserm U630, INSA-Lyon, Université Lyon1, Villeurbanne, France (email: olivier.beuf@univ-lyon1.fr). dedicated receiver coils for specific organs.

Multi-channel coils also called phased-array coils are developed to increase signal sensitivity and Signal to Noise Ratio (SNR) which are important parameters of NMR receiver coils [7], [8]. These coils are usually used in receiving mode only. In this case another larger volume coil with a more uniform excitation is used. An active decoupling circuit is added on each loop of the multichannel coil to actively drive the loop on resonance during the receiving phase and out of resonance during the transmitting phase.

These multi-channel coils are widely used for clinical applications [9]-[14] but much less developed for small animal applications [15], [16] due to the smaller number of dedicated MR systems available worldwide. So as to reduce mutual coupling in these multi-channel coils, two solutions are put forward.

The first technique consists in overlapping several single coil elements. Overlapping is optimized using electromagnetic equations and/or simulations using finite element method or method of moments [18] seeking out the lowest mutual coupling between the two channels [17]. Additional decoupling can be achieved with low input impedance and low noise figure preamplifiers [9], [19] in particular when more than two elements are used.

The second option is based on a common conductor between the loops. In this case, multi-channel coil is not composed of overlapped single coil elements but of electrically jointed loops with a common section of conductor. Decoupling between loops is achieved with a capacitor in series with the common conductor. This technique usually used in two-channel coils is more easily implemented that the overlapping process for low size multi-channel coil elements. Moreover, using this method, the loop areas are slightly smaller than in the overlapping case thus increasing slightly their expected sensitivity. These different reasons explain the recent development of this technique for small animal applications. The main advantage of the two-channel coil using common conductor is that it does not require preamplifier decoupling technique. In this case, the two-channel coil can therefore be made smaller and be used at higher frequency when space is limited inside the gradient. Moreover both transmitting and receiving phase (transceiver) can be combined on the same device [20]. However the theoretical equations of this common conductor decoupling technique are not explicitly given. To our knowledge, few recent works utilized this technique for human application. A paper presented two sensors based on a two-channel coil with a common conductor. These two sensors formed a four-channel coil for 
human cardiac application at 7T [21]. The authors took advantage of the surface coils to avoid the low efficiency of volume coil in the high-field regime. Their transceiver coil did not use preamplifier decoupling technique: decoupling between the two elements of the coil is achieved by the common section and decoupling between the two sensors is assured by the distance between themselves. This work shows that this decoupling technique is interesting for transceiver coil design and for high-field applications.

In this paper, in order to define some design rules for future realizations, we propose an equivalent circuit and, based on common conductor decoupling, develop theoretical equations associated to a two-channel coil. This study is based on an impedance transformation approach, usually used in radiofrequency circuits design. Simple circuit simulations of S-parameters were achieved to demonstrate the circuit behavior such simulations are not time consuming compared to electromagnetic simulations. Mandatory inductance and resistance values used in the circuit simulations should be obtained either by analytical calculations or electromagnetic simulations. Generally, authors only present dimension and component values of their coil designs. This paper insists on equivalent electrical circuit of the two-channel coil. Theoretical and practical studies had been performed to validate this circuit.

The equivalent electrical circuit of a two-channel coil with a common conductor is described in section II; the equations associated to this circuit are described in section III and are validated in section IV by S-parameters circuit simulations. A two-channel coil design is described in section $\mathrm{V}$ and measured in section VI. Finally retrospective simulations matching experimental results are presented.

\section{EQUIVALENT ELECTRICAL CIRCUIT}

A simplified physical topology of a two-channel NMR coil with a common conductor is shown in Fig. 1a): strip conductors form the two loops of the coil and lumped elements are added to match each loop. The equivalent electrical circuit of the coil is proposed in Fig. $1 \mathrm{~b}$ ). Two $\left(L_{b}-R-C_{c}-L_{c}-C_{d}\right)$ resonant single loops connected with the $\left(L_{c}-C_{c}\right)$ common section form the coil. The NMR signal measured with the two magnetic dipoles (loops) is sent to the data acquisition cabinet using $50 \Omega$ BNC coaxial cables. These connections are represented by two $50 \Omega$ ports in Fig. $1 \mathrm{~b})$. The $C_{a}$ capacitors are used for coil matching. The resistors $R$ represent the sum of conductor losses, magnetic losses and series resistances of lumped elements. The $L_{b}$ and $L_{c}$ inductors represent the loop conductor inductance and the common conductor inductance, respectively. In practice, the length of the conductors forming the coil is fixed by the imaging area of interest: $L_{b}$ and $L_{c}$ are fixed by the width $l$, the length $L$ of the coil and by the conductor width $W$ and thickness. a)
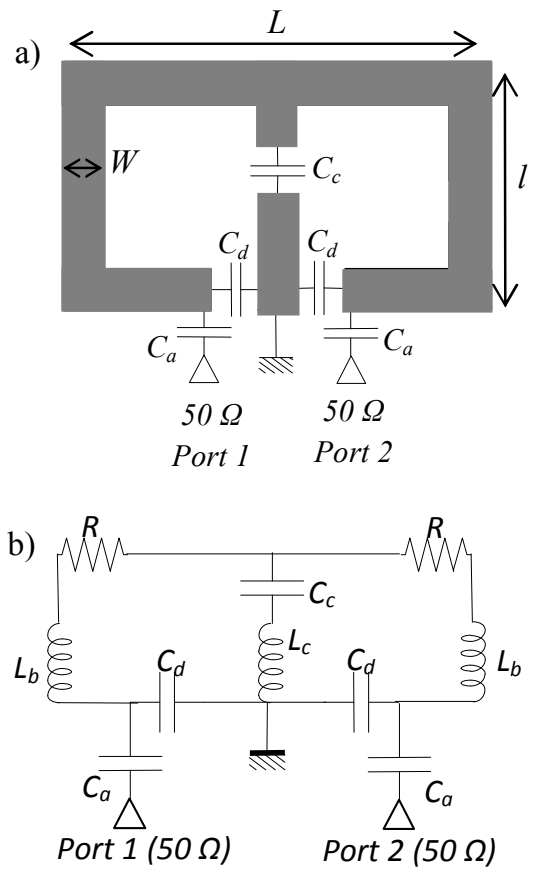

Fig. 1 a) Physical topology. b) Equivalent electrical circuit for a twochannel NMR coil.

\section{DESIGN EQUATIONS}

\section{A. Channels Decoupling}

Decoupling between channels is an important characteristic to obtain good image quality. Indeed if two loops are placed near each other, their mutual inductance results in splitting of the original resonance into two resonances. The sensitivity of the coils at the operating frequency is then greatly reduced [9]. The channel decoupling is required to restore the original resonance and original sensitivity. To achieve a perfect decoupling, the two loops must be independent: no transmission between the channels at the operating frequency. For multi-channel coils using single coil elements a magnetic decoupling is applied: coupling between elements is reduced by overlapping the single coils; the decoupling phenomenon is increased by employing low input impedance preamplifiers [9]. To perform this decoupling on the two-channel coil with a common conductor (Fig. 1), an electrical decoupling is achieved: the $L_{c}-C_{c}$ section has to short the loops in order to prevent any transmission between the two elements. The ground is deported between the two resistors $R$ (represented by a black point in Fig. 1b)). A perfect zero of transmission is obtained when:

$$
\left|j L_{c} \omega\right|=\left|\frac{1}{j C_{c} \omega}\right|
$$

with $\omega=2 \pi f_{0}$, where $f_{0}$ is the operating frequency.

When condition (1) is met, the two loops are decoupled and each loop can be considered as a single coil equivalent electrical circuit (Fig. 2) at the $f_{0}$ operating frequency.

\section{B. Loops Matching}

The decoupled loops can be independently matched to $Z_{0}=50 \Omega$. Fig. 3 shows impedance transformations achieved 
by the different elements of each loop. The $L_{b}-R$ section of the coil (Fig. 2) transforms the ground into a $Z_{b}$ ' complex impedance by adding a $j L_{b} \omega+R$ impedance. The $C_{d}$ parallel capacitor adds a $j C_{d} \omega$ pure imaginary admittance to create the $Z_{b}$ complex impedance. The $C_{a}$ series capacitor subtracts a $-j / C_{a} \omega$ pure imaginary impedance giving the $Z_{0}$ port impedance.

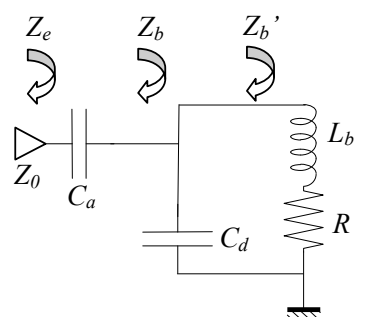

Fig. 2 Equivalent electrical circuit at the coil operating frequency.

The $Z_{b}$ loop input impedance is given by:

$Z_{b}=\frac{R}{\left(1-L_{b} C_{d} \omega^{2}\right)^{2}+\left(R C_{d} \omega\right)^{2}}+j \frac{L_{b} \omega-R^{2} C_{d} \omega-L_{b}{ }^{2} C_{d} \omega^{3}}{\left(1-L_{b} C_{d} \omega^{2}\right)^{2}+\left(R C_{d} \omega\right)^{2}}$

This equation shows that the real part of $Z_{b}$ impedance depends on the $R$ and exists only if $R$ is different from zero. The $C_{a}$ capacitor enables adjusting the imaginary impedance and adapting the coil at the $50 \Omega$ port.

$Z_{e}=Z_{b}-\frac{j}{C_{a} \omega}$

Real and imaginary parts matching of $Z_{b}$ impedance gives two equations linking $R, L_{b}, C_{d}$ and $C_{a}$ values:

$$
\begin{aligned}
& \frac{R}{\left(1-L_{b} C_{d} \omega^{2}\right)^{2}+\left(R C_{d} \omega\right)^{2}}=Z_{0} \\
& \frac{L_{b} \omega-R^{2} C_{d} \omega-L_{b}{ }^{2} C_{d} \omega^{3}}{\left(1-L_{b} C_{d} \omega^{2}\right)^{2}+\left(R C_{d} \omega\right)^{2}}-\frac{1}{C_{a} \omega}=0
\end{aligned}
$$

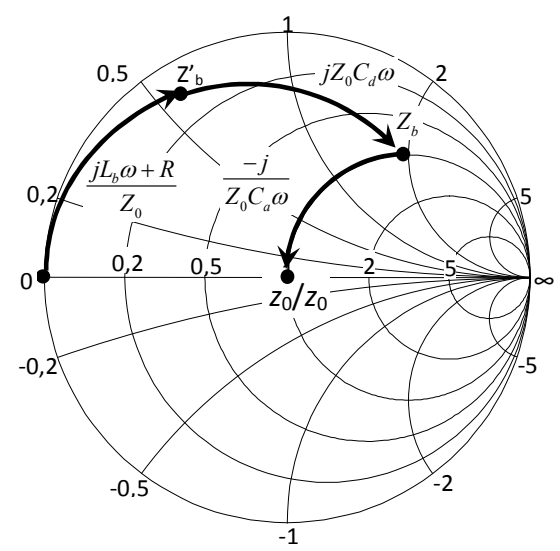

Fig. 3 Impedance transformations on the Smith chart.

\section{Tunable Elements}

The $Z_{e}$ input impedance has to be adjustable to match the loops in the magnet when the coil is placed on the animal. Indeed the background around the coil (animal and metallic magnet bore) shifts impedance and resonant frequency of each element. To adapt the real and imaginary loop impedances, two out of the three $L_{b}, C_{d}$ or $C_{a}$ parameters must be adjustable. Variable capacitance can be realized with mechanically adjustable capacitor or with varicap diodes. Variable inductance can be obtained with a fixed inductor in series with a variable capacitor as reported in previous work [22].

\section{Circuit Simulation Results}

To validate the two-channel coil equivalent electrical circuit and equations presented in the previous section, circuit simulations were carried out with Designer software (Ansys, USA). Physical dimensions of the Fig. 1a) design were specified by the imaging area of interest corresponding to the rat's brain coverage $(L=30 \mathrm{~mm}, l=52 \mathrm{~mm})$ at $7 \mathrm{~T}$. Loop conductors were fixed to $35 \mu \mathrm{m}$ thickness and $4 \mathrm{~mm}$ width section of copper tape. Inductance values were obtained using Grover formula [24]: The $L_{c}$ inductance is evaluated to $10.5 \mathrm{nH}$ and $L_{b}$ to $42 \mathrm{nH}$. These values are introduced in equations (1) (4) (5) to extract the $C_{c}, C_{d}$ and $C_{a}$ capacitances; $\mathrm{R}$ value is fixed to $1.1 \Omega$ corresponding to a realistic value of the real device and the operating frequency is fixed to $f_{0}=300 \mathrm{MHz}$ corresponding to the proton Larmor frequency in a $7 \mathrm{~T}$ static magnetic field:

- The equation (1) gives $C_{c}$ value as $26.8 \mathrm{pF}$.

- $C_{d}=5.7 \mathrm{pF}$ and $C_{a}=1 \mathrm{pF}$ were calculated with equations (4) and (5) in order to match the loops at $50 \Omega$ ports (these values are reported in Table I).

The electrical circuit of the Fig 1 was simulated: the $\mathrm{S}$ parameters results are presented in Fig 5 a). Since $S_{11}=S_{22}$ and $S_{21}=S_{12}$ for passive symmetric circuit, only $S_{11}$ and $S_{21}$ modulus results are presented. $\left|S_{11}\right|<-20 \mathrm{~dB}$ shows the matching of each channel and $\left|S_{21}\right|<-20 \mathrm{~dB}$ shows decoupling between the two channels with a zero of transmission $\left(\left|S_{21}\right| \rightarrow-\infty \mathrm{dB}\right)$ at the operating frequency. This simulation validates design equations presented in section III and the extraction of capacitance values. The $C_{a}$ value equal to $1 \mathrm{pF}$ is small for a real construction of the coil with Surface Mounted Components (SMC). To increase the $C_{a}$ value, $L_{b}$ value must be decreased to keep the impedance matching. These impedance transformations are deduced from Fig. 3. As the length of the conductors forming the coil is fixed by the imaging area of interest, the total inductance of a loop is also fixed. The inductance $L_{b}$ (Fig. 1b)) can be reduced by adding a $C_{b}$ capacitor in series with the loop conductor (equation (6)): $L_{b}$ of Fig. 1b) is replaced by $L_{b}$ ' in series with $C_{b}$ (Fig. 4); where $L_{b}$ ' is the loop conductor inductance and $L_{b}$ the inductance used in equations (2), (4) and (5).

$$
j L_{b} \omega=j L_{b}^{\prime} \omega+\frac{1}{j C_{b} \omega}
$$

The inductance of a loop $L_{b}$ ' remains equal to $42 \mathrm{nH}$ and $L_{b}$ is reduced to $7.42 \mathrm{nH}$ by adding a capacitor $C_{b}=8.14 \mathrm{pF}$ (equation (6)). The new values of $C_{a}$ and $C_{d}$ using equations (4) and (5) are $6.6 \mathrm{pF}$ and $33 \mathrm{pF}$ respectively. 


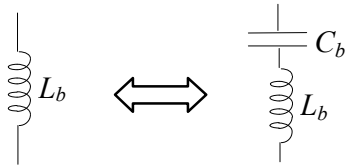

Fig. $4 L_{b}$ reduction by adding a series $C_{b}$ capacitor.

Curves in Fig. 5 b) show S-parameter modulus with $C_{a}=6.6 \mathrm{pF}, C_{c}=26.8 \mathrm{pF}, C_{d}=33 \mathrm{pF}, L_{b}=7.42 \mathrm{nH}$ and $L_{c}=10.5$ $\mathrm{nH}$. The matching of each channel $\left(\left|S_{11}\right|<-20 \mathrm{~dB}\right)$ and the zero of transmission $\left(\left|S_{21}\right| \rightarrow-\infty \quad \mathrm{dB}\right)$ at the operating frequency confirms the new capacitance values.

Curves in Fig. 5 c) show S-parameter modulus replacing the inductance $L_{b}$ by an inductor $L_{b}{ }^{\prime}=42 \mathrm{nH}$ in series with a capacitor $C_{b}=8.14 \mathrm{pF}$ and using the same $C_{a}, C_{c}, C_{d}$ capacitor values as in Fig. 5 b). S parameters of Fig. 5 a) and b) confirm the coil equivalent electrical circuit. These curves also validate equations (4) and (5) which yield the component values giving a good adaptation of the loops and a perfect decoupling between elements. Fig. 5 a) and c) are superposed showing the equivalence between the two electrical circuits using the same inductors but different capacitor values. Comparison between Fig. 5 b) and c) confirm the equivalence between $L_{b}$ and $L_{b}$ ' in series with $C_{c}$ at the operating frequency.

We can see on Fig. 5 that the quality factor $(Q)$ increases when the loop inductance increases (comparison between Fig. 5 a) and b)). This observation is consistent with the given definition of quality factor for a single coil element: $Q=\omega L / R$ where $L$ is the loop inductance of the coil and $R$ its resistance. This definition is confirmed by Fig. 5 a) and c) where the quality factor depends only on loop inductance and resistance; capacitor values do not modify this quality factor. Note that quality factor measured at $50 \Omega$ and called $Q_{L}$ (for loaded quality factor) is given by $Q_{L}=Q / 2$ [16], [23].

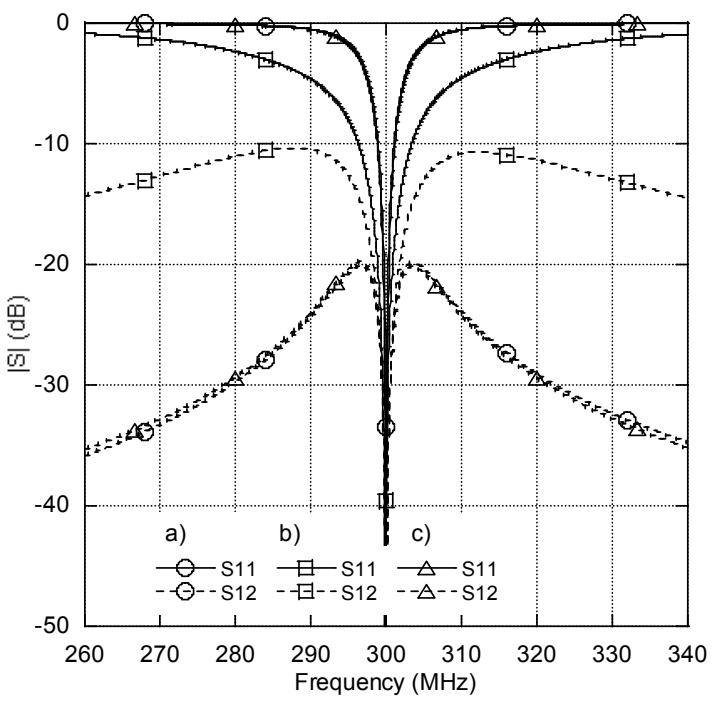

Fig. $5|\mathrm{~S}|$ parameters simulations of the coil a) with $L_{b}=42 \mathrm{nH}$, b) with $L_{b}=7.4 \mathrm{nH}$ and c) with $L_{b}{ }^{\prime}=42 \mathrm{nH}$ in series with $C_{b}=8.1 \mathrm{pF}$.

These circuit simulations validate the electrical circuit and the equations established in the previous section:
- The common conductor composed of $L_{c}$ and $C_{c}$ elements is only useful for decoupling between the two loops.

- This common conductor does not interfere with the loop functioning at the operating frequency (Fig. 2).

\section{V.DESIGN}

To validate theoretical and simulated results with experimental results, a two-channel NMR coil was built. This coil was designed for rat brain imaging and to be used on a Bruker $7 \mathrm{~T}$ Biospec MR scanner (Bruker, Ettlingen, Germany). Using hybrid technology, the coil was built on a flexible substrate so as to fit the animal's morphology. Each coil element was matched to $50 \Omega$ at the proton Larmor frequency in a $7 \mathrm{~T}$ static magnetic field, i.e. $f_{0}=300 \mathrm{MHz}$. Fig. 6 illustrates the NMR receiver coil.

To decouple the receiver coil from the transmitter coil (active decoupling), each loop integrated an active decoupling circuit made with two parallel DH80055 PIN diodes (Temex Ceramics, Pessac, France) biased at 3.8 V. These diodes are placed in series with the $L_{b}$ inductance to detune the surface coil during the transmission phase. Two $50 \mathrm{~cm}$ length BNC cables were soldered at the two loop inputs (50 $\Omega$ ports on Fig. 6) to connect the coils to the acquisition data cabinet.

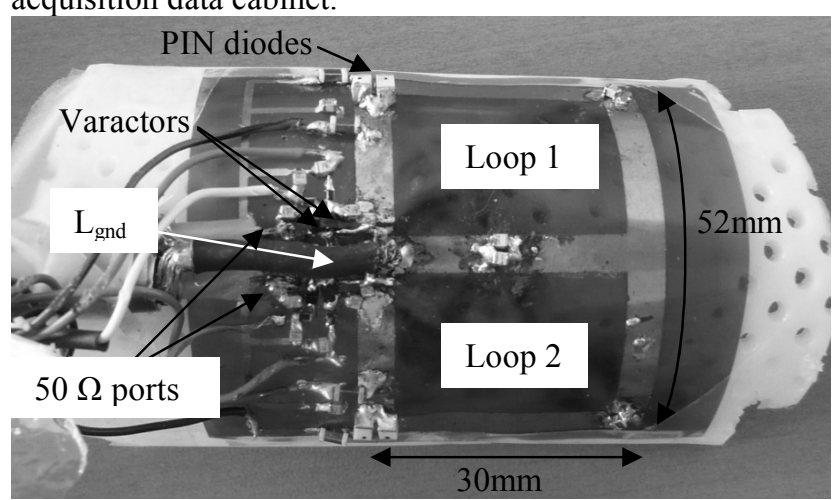

Fig. 6 Photograph of the two-channel NMR coil.

\section{A. Inductors}

Inductor values were determined using Grover formula [24]. The $L_{c}$ inductor is in the range of $9.9 \mathrm{nH}$ to $14.7 \mathrm{nH}$ for a conductor length between $23 \mathrm{~mm}$ and $30 \mathrm{~mm}$. The $L_{b}$, inductor is between $33.1 \mathrm{nH}$ and $46.9 \mathrm{nH}$ for a conductor length between $63 \mathrm{~mm}$ to $80 \mathrm{~mm}$. Conductor length error presented in Fig. 7 depends on the internal/external loop measurements $\Delta l_{1}$ but also on measurement under the SMC soldering $\Delta l_{2}$.

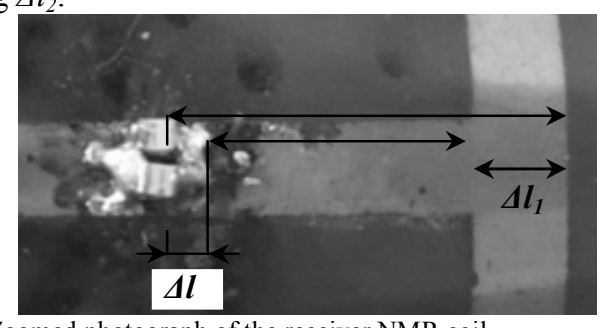

Fig. 7 Zoomed photograph of the receiver NMR coil. 


\section{B. Variable Elements}

The $L_{b}$ inductance and the $C_{a}$ capacitance are chosen to be the two variable elements. $L_{b}$ was realized using an $L_{b}$, inductor in series with a $C_{b}$ capacitor. $C_{a}$ and $C_{b}$ capacitances enabled tuning and matching for each loop. $C_{a}$ capacitance is achieved with one variable capacitance diode BB149 (Philips Semiconductors, Eindhoven, Netherlands) varying from $2 \mathrm{pF}$ to $20 \mathrm{pF}$ for a bias voltage varying respectively from $-30 \mathrm{~V}$ to $0 \mathrm{~V}$. $C_{b}$ capacitance is realized with a variable capacitance diode BB149 and three fixed capacitors (in series and parallel). $C_{b}$ capacitance varies from $6.8 \mathrm{pF}$ to $8.5 \mathrm{pF}$ for diode bias voltage varying respectively between $-30 \mathrm{~V}$ and $0 \mathrm{~V}$. The tuning/matching and active decoupling circuits were designed to be interfaced and driven by the "cross coil interface unit" from the Bruker system. The "cross coil interface unit" gives a bias voltage for PIN diodes command $(-32 \mathrm{~V}$ or $3.8 \mathrm{~V}$ for active decoupling/coupling) and four variable bias voltages (varying from $-32 \mathrm{~V}$ to $-1 \mathrm{~V}$ ) for both tuning/matching of each loop.

Tunable elements and their bias circuits require some free space on the coil. Therefore ground and $50 \Omega$ ports were moved a few centimeters away. This line extension adds an $L_{\text {gnd }}$ parasitic inductance between the ground and the coil presented in Fig. 6.

\section{Capacitors}

$C_{c}$ and $C_{d}$ capacitors are non magnetic case A series 100 ATC capacitors (American Technical Ceramics, New York, USA). The $C_{c}$ value was experimentally adjusted to minimize the $\left|S_{12}\right|_{d B}$ parameter between the two channels at the operating frequency. $C_{c}$ is composed of four fixed capacitors in parallel $(12 / / 10 / / 2.2 / / 2.2=26.4 \pm 2.6 \mathrm{pF})$ while $C_{d}$ is a single fixed capacitor with a value of $33 \pm 3.3 \mathrm{pF}$.

\section{D.Resistance}

The $R$ series resistance of the coil is one of the most important parameter to reach a good quality factor. This equivalent series resistance depends on the parasitic resistance of SMC elements, on the conductor resistance and on the magnetic losses.

Resistance due to SMC elements can be estimated using manufacturer's datasheet:

- ATC capacitors have an ESR equivalent series resistance (in ohm) which depends on the CapaVal capacitor value in $\mathrm{pF}$. ESR can be given by :

$$
E S R=1.23 * \text { Capa Val }^{-0.62}
$$

- Series resistance of PIN diodes is $0.25 \Omega$ maximum at $120 \mathrm{MHz}$ for a $50 \mathrm{~mA}$ current.

- Series resistance of BB149 varicaps is $0.75 \Omega$ maximum at $470 \mathrm{MHz}$.

The total estimated series resistance taking into account all SMC elements was about $1.24 \Omega$ maximum.

Conductor resistance calculated at $300 \mathrm{MHz}$ for a $4 \mathrm{~mm}$ x $35 \mu \mathrm{m}$ section of copper was $0.56 \Omega / \mathrm{m}$. For about $10 \mathrm{~cm}$ length loop, the resistance was around $0.056 \Omega$ which is negligible compared to the equivalent series resistance of the SMC elements.

\section{RESULTS}

\section{A. $|S|$ Parameters Measurements}
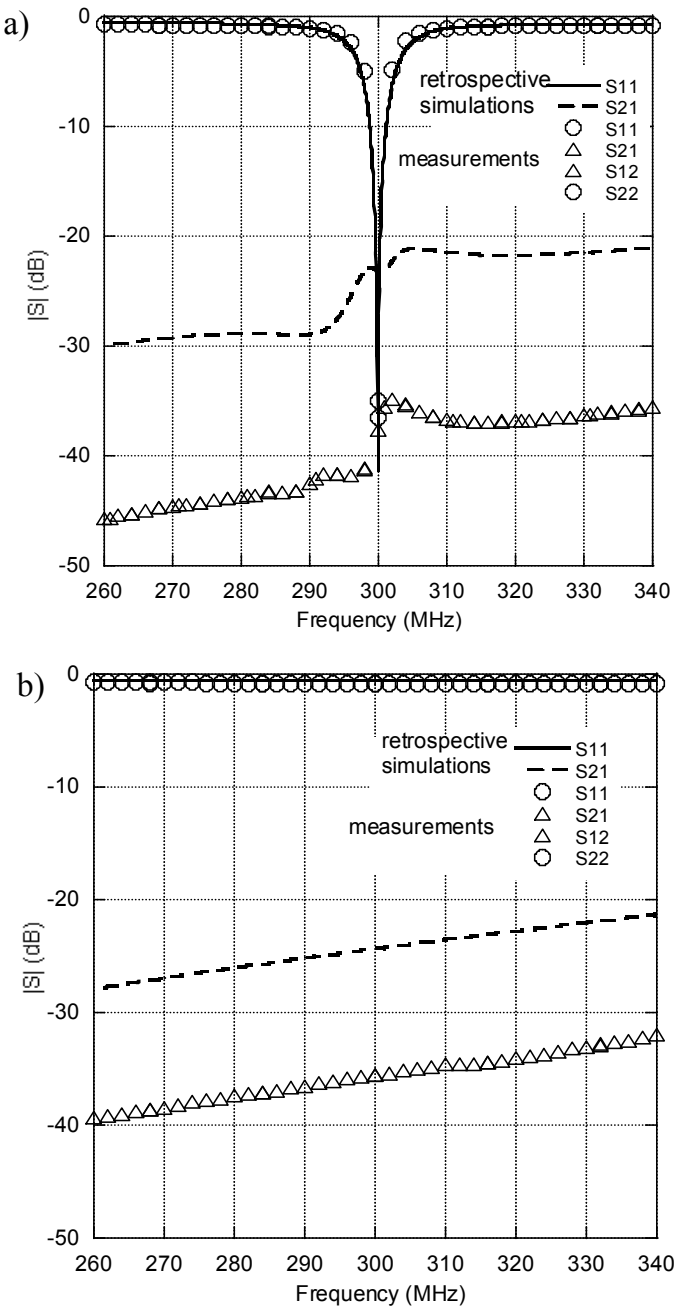

Fig. 8 Retro-simulated and measured results of the coil loaded by a cylindrical phantom of saline water. a) coil is matched; b) coil is detuned.

The coil presented in Fig. 6 was measured with an Agilent ENA300 Vector Network Analyzer (Agilent Technologies Inc., Santa Clara, CA, USA). Fig. 8 shows measurements on the coil which has been loaded with a 35 $\mathrm{mm}$ diameter and $10 \mathrm{~cm}$ length cylindrical phantom filled with saline water $(5 \mathrm{~g} / \mathrm{L}$ of $\mathrm{NaCl}$, conductivity of about 1 $\mathrm{S} / \mathrm{m}$ ) to mimic a rat inside the coil. For the first channel $C_{a l}$ was biased by $V_{C a l}=-7.6 \mathrm{~V}$ and $C_{b 1}$ was biased by $V_{C b I}=-2.1$ $\mathrm{V}$. The second channel was biased with $V_{\mathrm{Ca} 2}=-7.9 \mathrm{~V}$ and $V_{C b 2}=-3 \mathrm{~V}$ to independently match the loops to the $50 \Omega$ port. Capacitance values of diode BB149 could be extracted from datasheet. Manufacturer capacitance value versus diode bias voltage is shown in Fig. 9. The $-8 \mathrm{~V}$ and $-7.6 \mathrm{~V}$ voltage values approximately give $C_{a l}=6 \mathrm{pF}$ and $C_{a 2}=6.5 \mathrm{pF}$ respectively. The $-3 \mathrm{~V}$ and $-2 \mathrm{~V}$ voltage values correspond to about $12 \mathrm{pF}$ and $15 \mathrm{pF}$ diodes capacitances. Because $C_{b}$ is composed of a diode with three fixed capacitors (in series and parallel), the equivalent values $C_{b}$ for each channel are 
$C_{b 1}=8.1 \mathrm{pF}$ and $C_{b 2}=8.2 \mathrm{pF}$. Loops were matched at $50 \Omega$ for $300 \mathrm{MHz}$ and a good decoupling (better than $-35 \mathrm{~dB}$ over all frequencies) was achieved between the two elements. Experimental and retroactive simulation (detailed in the next paragraph) results are shown in Fig. 8, a) when PIN diodes is activated, i.e. the coil is matched and b) blocked, i.e. the coil is detuned. The independently tuned $\left|S_{11}\right|$ and $\left|S_{22}\right|$ parameters are superposed in Fig. 8 and show the good matching for each loop. In the same way, $\left|S_{12}\right|$ and $\left|S_{21}\right|$ parameters exhibited a similar level in each transmission direction. Quality factor of each loop was measured at $-3.5 \mathrm{~dB}$ on the $\left|S_{11}\right|$ and $\left|S_{22}\right|$ parameters for coil unloaded and loaded, taking into account the $-0.5 \mathrm{~dB}$ losses observed in measurements on the whole frequency band. Quality factors of 78 and 89 are obtained respectively for the two loops of the unloaded coil; 52 and 55 for the loaded coil.

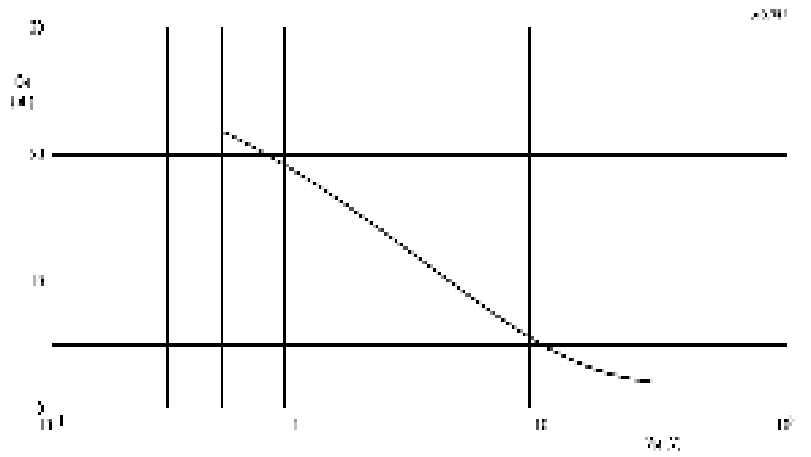

Fig. 9 Typical capacitance values of diode BB149 versus reverse voltage; extracted from manufacturer datasheet.

These measured results are not in good agreement with the circuit simulations corresponding to the design. Indeed the zero of transmission $\left(\left|S_{12}\right| \rightarrow-\infty \mathrm{dB}\right)$ observed in simulation (Fig $5 \mathrm{c})$ ) at the operating frequency is not obtained in measurements (Fig. 8). Moreover the measured transmission curves $\left(\left|S_{12}\right|\right.$ and $\left.\left|S_{21}\right|\right)$ are distorted compared to the simulation curve which is symmetric around $f_{0}$.

\section{B. Retrospective Simulations}

The equivalent electrical circuit of the two-channel NMR coil was modified to understand the difference between measurements and first simulations. Two elements presented in Fig. 10 have been added in the circuit: an $L_{g n d}$ inductor and two $50 \Omega$ loss transmission lines representing the parasitic inductance connected between the ground plane and the coil and the coaxial cables connected at the loop input, respectively. To fit retrospective simulations with measured results $L_{\text {gnd }}$ is tuned to $4 \mathrm{nH}$ and $0.54 \mathrm{~dB} / \mathrm{m}$ of loss are added in the transmission lines. In the detune mode, a capacity of $4 \mathrm{pF}$ was added in series with $L_{b}$ ' to represent the two parallel PIN diodes. The other component values were kept identical as in section IV in agreement with the coil design $\left(R=1.1 \Omega, C_{a}=6.6 \mathrm{pF}, C_{d}=33 \mathrm{pF}\right.$, $L_{c}=10.5 \mathrm{nH}, C_{c}=26.8 \mathrm{pF}, L_{b}{ }^{\prime}=42 \mathrm{nH}$ in series with $C_{b}=8.14$ pF). Fig. 8 b) illustrates that the transmit/receive decoupling is well achieved and also validates the equivalent electrical circuit in detune mode.
Additional retrospective simulations have shown that the effect of the ESR distribution on each component can be neglected compared to the $L_{\text {gnd }}$ parasitic inductance and losses in transmission lines. Indeed this effect is localized near the operating frequency and does not explain curve distortion over all frequencies.

The retrospective simulation and the measured results are superposed in Fig. 8. Comparison between the simulations (Fig. 5 c)) and retrospective simulations show (Fig. 8) that:

- the $L_{\text {gnd }}$ inductance impairs the perfect zero of transmission at the operating frequency and distorts the transmission curve,

- the loss transmission lines add $-0.5 \mathrm{~dB}$ on $\left|S_{11}\right|$ parameter over all frequencies.

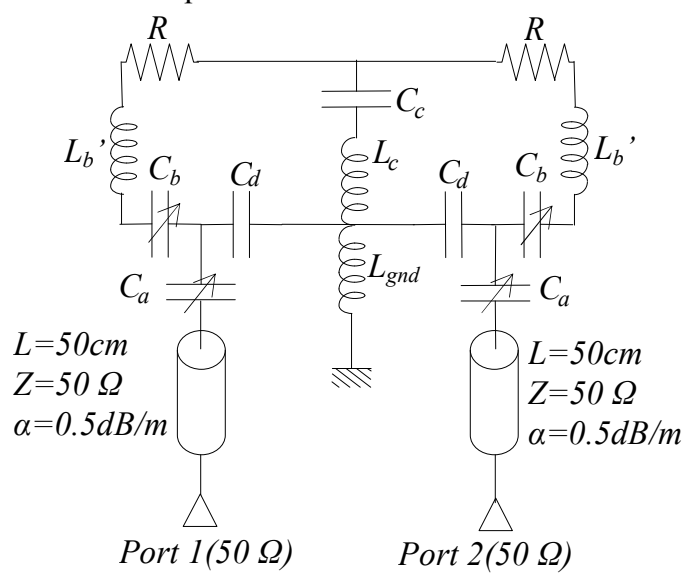

Fig. 10 Equivalent electrical circuit of a two-channel NMR coil taking into account the $L_{\text {gnd }}$ parasitic inductance and the coaxial input cables.

Retrospective simulations and measurements presented in Fig. 8 are now in good agreement. Only a $15 \mathrm{~dB}$ difference remains on the transmission between loops ( $\left|S_{21}\right|$ in Fig. 8); a better decoupling is observed in measurements compared to simulation prediction. More rigorous electromagnetic simulations taking into account all dielectric, magnetic and radiation losses might lead to a better understanding of this mismatch.

The values of all elements used for calculation, simulations and in the design of the coil are summarized in Table 1. It shows the coherence between calculation, simulations and design, validating the equivalent electrical circuit and the equations of the two-channel NMR coil.

\section{C.Magnetic Resonance Imaging}

To validate the RF coil use, two morphologic rat brain images acquired at $7 \mathrm{~T}$ are presented in Fig. 11. The sequence was used with the following parameters: FOV $=26 \times 26 \mathrm{~mm}^{2}, 384 \times 512$ matrix size, 5 slices of $3 \mathrm{~mm}$ thickness, $50 \mathrm{kHz}$ receiver bandwidth (rbw), $\mathrm{TR} / \mathrm{TE}=661.6 / 59.4 \mathrm{~ms}$. A transmit birdcage coil with 112 $\mathrm{mm}$ outer diameter and $72 \mathrm{~mm}$ inner diameter (Bruker, Germany) was employed for RF pulses excitation and a surface coil especially designed for rat brain imaging was used in receiving mode only. Fig. 11 a) and Fig. 11 b) show results obtained with a $25 \mathrm{~mm}$ inner diameter single coil and with the two-channel coil (Fig. 6), respectively. For each 
TABLE I

SUMMARIZATION OF ELEMENTS VALUES USED AND OBTAINED IN CALCULATION, SIMULATION AND DESIGN.

\begin{tabular}{|l|l|l|l|l|l|l|l|l|}
\hline & $L_{c}(\mathrm{nH})$ & $L_{b}(\mathrm{nH})$ & $L_{b}{ }^{\prime}(\mathrm{nH})$ & $C_{b}(\mathrm{pF})$ & $R(\Omega)$ & $C_{a}(\mathrm{pF})$ & $C_{c}(\mathrm{pF})$ & $C_{d}(\mathrm{pF})$ \\
\hline Calculation & 10.5 & 7.42 & 42 & 8.14 & 1.1 & 6.6 & 26.8 & 33 \\
\hline Simulation Fig. 6 a) & 10.5 & 42 & & & 1.1 & 1 & 26.8 & 5.7 \\
\hline Simulation Fig. 6 b) & 10.5 & 7.42 & & & 1.1 & 6.6 & 26.8 & 33 \\
\hline Simulation Fig. 6 c) & 10.5 & & 42 & 8.14 & 1.1 & 6.6 & 26.8 & 33 \\
\hline Retro. simulation & 10.5 & & 42 & 8.14 & 1.1 & 6.3 & 26.8 & 33 \\
\hline Design & 9.9 to & & $\begin{array}{l}33.1 \text { to } \\
46.9\end{array}$ & $\begin{array}{l}\mathrm{C}_{\mathrm{b} 1}: 8.1 \\
\mathrm{C}_{\mathrm{b} 2}: 8.2\end{array}$ & $\begin{array}{l}1.24 \\
\text { max }\end{array}$ & $\begin{array}{l}\mathrm{C}_{\mathrm{a} 1}: 6 \\
\mathrm{C}_{\mathrm{a} 2}: 6.5\end{array}$ & 26.4 & 33 \\
\end{tabular}

receiver coil, SNR value was measured on two regions of interest (ROI) presented in Fig. 11. First ROI is placed at $2.5 \mathrm{~mm}$ from the coil. The second ROI is placed at $1 \mathrm{~cm}$ from the coil, in the deep brain area including the olfactory cortex. A 7.2 \pm 2 mean SNR was measured for the single coil and $14.7 \pm 3.6$ was obtained for the two-channel coil. Use of the two-channel coil nearly doubles the measured SNRvalue compared to that of the single coil.

These MRI results validate the coil design and confirm the advantage of a two-channel surface coil compared to a single coil; acquisition times can be divided by four thanks to the improved SNR. This two-channel coil is interesting for functional or high resolution MRI applications where SNR and acquisition time are important parameters.
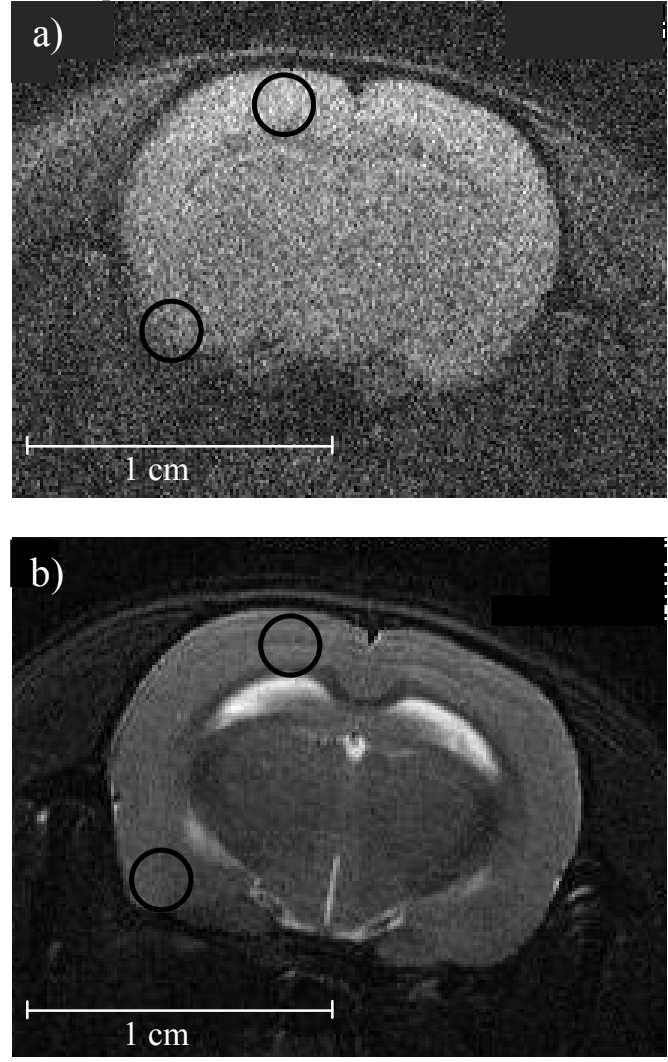

Fig. 11 Morphologic rat brain MR imaging a) with a single coil, b) with the two-channel coil.

\section{CONCLUSION}

Equations to design a two-channel NMR coil have been established using an impedance transformation approach. They were validated by circuit simulations, design of a twochannel coil and the measurements of characteristic parameters. Finally, the coil was successfully tested on morphologic rat brain images acquired at 7T. A better modeling of the inductance values introduced in equivalent electrical circuit could be obtained using electromagnetic simulations based on finite element method or method of moments. Comparisons between circuit simulations and measurements have demonstrated the influence of the most important parasitic element: the $L_{\text {gnd }}$ parasitic inductance. This element has to be considered in the equivalent electrical circuit for future conception. Complementary studies of the design are intended to minimize the parasitic inductance and to restore the ideal zero of transmission between the two channels.

\section{REFERENCES}

[1] A. Asfour "Design and development of a new dedicated RF sensor for the MRI of rat brain," J. Biomedical Science and Engineering, vol. 3, pp. 167-180, 2010.

[2] A. Rengle, M. Armenean, R. Bolbos, J. C. Goebel, A. PinzanoWatrin, H. Saint-Jalmes, P. Gillet and O. Beuf "A dedicated twochannel phased array receiver coil for high resolution MRI of the rat knee cartilage at 7T," IEEE Trans Biomed Eng., vol. 56, pp. 28912897, 2009.

[3] R. C. Susil, C. J. Yeung and E. Atalar, "Intravascular Extended Sensitivity (IVES) MRI Antennas," Magnetic Resonance in Medicine, vol. 50, pp. 383-390, 2003.

[4] S. M. Wrightw and L. Wald, "Theory and Application of Array Coils in MR Spectroscopy,” NMR in, vol. 10, pp. 394-410, 1997.

[5] X. Zhang, K. Ugurbil, and W. Chen "Microstrip RF Surface Coil Design for Extremely High-Field MRI and Spectroscopy," Magn Reson Med, vol. 46, pp. 443-450, 2001.

[6] A. Rengle, H. Ratiney, A. Bucur, S. Cavassila, and O. Beuf. "Reconuration of a 'standard' Biospec spectrometer for simultaneous 2channel acquisitions: Application for mouse brain MRI and MRS," In IEEE Int Symp on Biomed Imag: From Nano to Macro, pp. 432435, Paris, France 2008.

[7] D. I. Hoult and R. E. Richards "The signal-to-noise ratio of the nuclear magnetic resonance experiment," J Mag Reson, vol. 24, Issue 1, pp. 71-85, 1976.

[8] Jianmin Wang, Arne Reykowski, and Johannes Dickas, "Calculation of the Signal-to-Noise Ratio for Simple Surface Coils and Arrays of Coils," IEEE Transaction on Biomedical Engineering, vol. 42, $\mathrm{n}^{\circ} 9$, pp. 908-917, sept. 1995.

[9] P. B. Roemer, W. A. Edelstein, C. E. Hayes, S. P. Souza and O. M. Mueller "The NMR phased array," Magn Reson Med, vol. 16, pp. 192-225, 1990.

[10] W. E. Kwok, J. Zhong, Z. You, G. Seo, S. M. S. Totterman “A fourelement phased array coil for high resolution and parallel MR imaging of the knee,” Magn Reson Imag, vol. 21, pp. 961-967, 2003. 
[11] N. De Zanche, J. A. Massner, C. Leussler and K. P. Pruessmann "Modular design of receiver coil arrays," NMR Biomed, vol. 21, pp. 644-654, 2008

[12] C. E. Hayes, N. Hattes, P. B. Roemer "Volume imaging with MR phased arrays" Magn Reson Med, vol. 18, pp. 309-319, 1991.

[13] Y. Ergaman, Y. Oner and E. Atakar "Design of internal MRI coils using ultimate intrinsic SNR" Magnc Reson. Mater Phy., vol. 22, pp. 221-228, 2009

[14] M. A. Bernstein, M. Crgic, T. J. Bronan, N. J. Pelc "Reconstructions of phase contrast, phased array multicoil data" Magn Reson Med, vol. 32, pp. 339-334, 1994.

[15] D. Gareis, T. Wichmann, T. Lanz, G. Melkus, M. Horn and P. M. Jakob "Mouse MRI using phased-array coils," NMR Biomed, vol. 20, pp. 326-334, 2006.

[16] F. D. Doty, G. Entzminger, J. Kulkarni, K. Pamarthy, and J. P. Staab "RF Coil Technology for Small-Animal MRI," NMR Biomed, vol. 20, pp. 304-325, 2007.

[17] P. Angelidis, K. Vassiliadis, and G. D. Sergiadis "Lowest Mutual Coupling Between Closely Spaced Loop Antennas," IEEE Trans Antennas and Propag, vol. 39, pp. 949-953, 1991.

[18] F. H. Lin, W. P. Kuan, S. K. Jeng, and J. H. Chen "Quantitative Spectral/Spatial Analysis of Phased Array Coil in Magnetic Resonance Imaging Based on Method of Moment," IEEE Trans Med Imag, vol. 18, pp. 1129-1137, 1999.

[19] A. Reykowski, S. M. Wright, J. R. Porter "Design of Matching Networks for Low Noise Preamplifiers," Magn Reson Med, vol. 33, pp. 848-852, 1995.

[20] D. Gareis, T. Neuberger, V. C. Behr, P. M. Jakob, C. Faber, M. A. Griswold "Transmit-receive coil-arrays at 17.6T, configurations for H-1, Na-23, and P-31 MRI," Concepts Magn Reson Part B, Magn Reson Eng, vol. 29B, pp. 20-27, 2006.

[21] M. A. Dieringer, W. Renz, T. Lindel, F. Seifert, T. Frauenrath, F. von Knobelsdorff-Brenkenhoff, H. Waiczies, W. Hoffmann, J. Rieger, H. Pfeiffer, B. Ittermann, J. Schulz-Menger, and T. Niendorf, "Design and Application of a Four-Channel Transmit/Receive Surface Coil for Functional Cardiac Imaging at 7T" Journal of Magnetic Resonance Imaging, vol. 33, pp. 736-741, 2011.

[22] A. Jrad, A. L. Perrier, R. Bourtoutian, J. M. Duchamp, and P. Ferrari "Design Of An Ultra Compact Electronically Tunable Microwave Impedance Transformer," Electron Lett, vol. 41, pp. 707-709, 2005.

[23] D. I. Hoult "The NMR receiver: a description and analysis of design," Progess in NMR Spectroscopy, vol. 12, pp. 41-77, 1978.

[24] F. W. Grover "Inductance Calculations: Working Formulas and Tables," 1946 \& 1973, Dover Phoenix Edition, 2004.

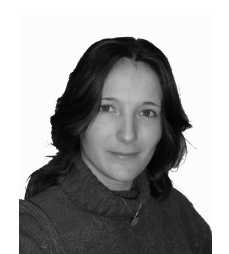

Anne-Laure Perrier was born in France in 1980. She received the M.Sc. degree in Optics, Optoelectronics, and Microwaves from the INPG ("Institut National Polytechnique de Grenoble"), Grenoble, France, in 2003. She received the Ph.D. degree in 2006 from the Laboratory of Microwaves and Characterization (LAHC), University of Savoie, France. Her research interests include the theory, design, and realization of tunable-impedance transformers.

She has been an Assistant Professor since September 2008 at Claude Bernard University (Lyon, France), where she teaches electronics and signal processing. She continues her research at the Research Center on Medical Imaging (Creatis-LRMN). She designs and realizes RF sensors for MRI (Magnetic Resonance Imaging) applications.

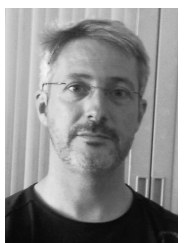

Denis Grenier is born in France in 1968. After a master in physics he received a $\mathrm{PhD}$ in biomedical engineering from Université Claude Bernard Lyon 1999. Post doctoral fellow at University of California San Francisco, he worked between 1999 and 2001 on MR sequence programming in the field of musculoskeletal application for UCSF radiology department and the field of Multiple Sclerosis for the neurology department. Since 2001 he is in charge of CREATIS UMR CNRS 5012 MR facility. He is part of the team "NMR and optics: Methods and systems". His research focuses on MR signal creation.

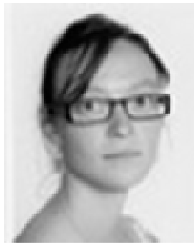

Audrey Pouzin was born in France in 1983. Audrey received her engineer degree from the Institute National Polytechnique de Grenoble (Grenoble-INP), Grenoble, France in 2006 and her Ph.D. degree in optical and radiofrequency engineering in 2009. Her main research interests are the characterization of RF systems, either in terms of regulations or the real performances observed in operations.

She was a Research Engineer since December 2009 at the CNRS (Lyon, France), where she worked on electronic and radiofrequency devices for MRI (Magnetic Resonance Imaging) applications. Currently, she is an engineer employed by the Xerox Company at Valence (France). Her job consists to test and validate local public transport system.

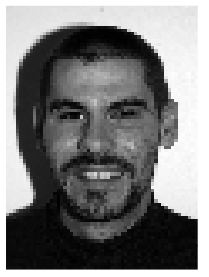

Frederic Esclassan was born in France in 1980 After his master's degree, he received the $\mathrm{PhD}$ degree from the Paul Sabatier University (Toulouse) in 2008 for his work on trace and delay fear conditioning.

After a postdoctoral fellowship in the Lyon Neuroscience Centre (2009-2011), he continued his work in Lilly Research Center (London). His research interests include behavioral and pharmacological

studies in rodents.

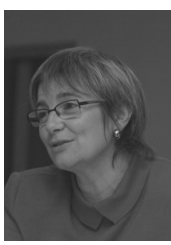

Nadine Ravel was born in France in 1960. After her master's degree in Neurosciences, she received the $\mathrm{PhD}$ degree from the Lyon 1 University in 1988 for her work on cholinergic modulation of olfactory perception and memory.

She has been headhunted as senior researcher by the CNRS in 1990 and continues her work in the Center for Research in Neuroscience (Lyon, France). Her research interests include brain dynamic and olfactory memory using several methodological approaches from electrophysiology to neuro-imaging in rodents.

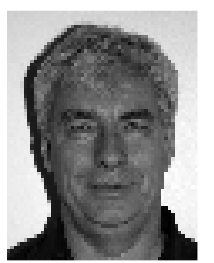

Philippe Litaudon was born in France in 1962. After the master's degree in Neurosciences in 1989, he received the $\mathrm{PhD}$ degree in 1993 from the Lyon 1 University. His thesis focused on the spatio-temporal representation of odors stimuli in the olfactory cortex using optical imaging approach.

He has been headhunted as senior researcher in 1998 and continues his works in the Neuroscience Centre (Lyon, France). His research interests include brain dynamic and odor processing in central olfactory pathways using several methodological approaches from electrophysiology to neuro-imaging in rodents.

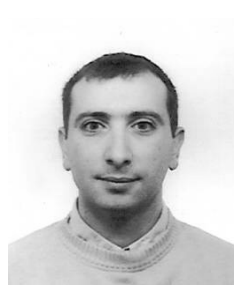

Olivier Beuf was born in France in 1970. He received his $\mathrm{PhD}$ degree in physics from the University de Lyon in 1998. From 1998 to 2000 he was a postdoctoral fellow at the University of California, San Francisco working on advanced methodological MRI developments for musculoskeletal applications. After a short position as MRI application specialist at Siemens Medical Solutions, France, he joined the CNRS 5012 NMR laboratory in 2000. Today, he is the head the research team entitled "NMR and optics: Methods and systems" from the CREATIS laboratory. His research mainly focuses on radiofrequency coils and sequence developments for medical or biological MRI applications both on human and small animals. 